Lautaro Yankas

\title{
El estilo y el hombre en Mariano Latorre
}

NA EXACTA definición del cuento y la novela en Amé-
y humana inéditas, y al mismo tiempo de sus grandes
promotores, situaría de inmediato en zona de privilegio a nuestro Mariano Latorre, cuya obra, sostenida y fecunda, decantó la escuela naturalista con páginas de real jerarquía estilística.

Sin embargo, en el cómodo recuento de valores continentales que las historias literarias echan a correr por tierras propias y extrañas, Latorre no exhibe la dimensión de acendrado forjador y de patriarca de una escuela que en admirable contienda de superación ennoblece el panorama de la literatura patria. Le ocurre lo que a otros maestros de América, valores decisivos en el alba espiritual de sus pueblos, en los cuales bebieron y se inspiraron los que hoy ya han superado las fronteras de la celebridad nacional. Junto a un Hupton Sincler, a un Martín Luis Guzmán, a un Azuela, o un Rivera, no baten cencerro un Bret Harte, un Javier de Viana, un Vicente Salaverri, un Abraham Valdelomar, un Jaime Mendoza, un García Calderón o un Mariano Latorre.

Por lo pronto, en una correcta perspectiva de valores, Latorre, definido en tres o cuatro libros fundamentales, no podría identifi- 
carse con aquéllos ni con éstos. Es inconfundible. $\mathrm{Y}$ lo es, entre otras razones, porque carece de las virtudes narrativas que ostentan, cual más, cual menos, todos ellos, teniendo, en cambio, otras personalísimas, que habremos de señalar luego.

Examinar en este momento las características del naturalismo no constituye real imperativo, pues esta escuela ha sido auscultada $y$ desmenuzada en toda forma, utilizando cuanto elemento de juicio pudiera reunir la sapiencia crítica y la beligerancia, sometiendo el proceso naturalista a presiones inauditas y a climas infernales. La escuela, repudiada en sus comienzos, se ha defendido con los aportes de la nueva sensibilidad y disfrazada de realismo no ha perdido una pulgada de terreno, pues comparte las preferencias del lector contemporáneo.

Interesa, sí, por sobre todo, el examen del objetivismo de Latorre, por su extraordinaria tónica, su unidad saludable, su holgura superada para hacer con ello un todo inconfundible, fresco, musical, claro, estable. No es fácil vertebrar tan recia y armónica estructura desde el primero al último pilar, desde su base hasta sus agujas cimeras. Más de una decena de libros la integran. Estamos, pues, ante una faena resuelta y nítida en que la exuberancia de algunas páginas cede ante la concertada armonía de los totales. Casi todos los escritores señalados más arriba en primer plano, se proyectan en una obra feliz que los lanzó de golpe a la fama. Latorre se vuelca en un conjunto de ancha base. Cuna de cóndores, su primera obra madura (antes había escrito Cuentos del Maule y algunos relatos dispersos en diarios y revistas), es seguida por Zurzulita, novela abrupta que el autor revisó años después; luego aparecen Chilenos del mar, On Panta, Hombres y zorros, Mapu y Viento de mallines. Sus obras restantes, Ully, El caracol y $\mathrm{La}$ isla de los pájaros, complementan la unidad impuesta por aquéllas. ¿Qué escritor en América podría ofrecernos tan bien sostenida trayectoria? He ahí, pues, una de sus excelencias.

Entremos ahora en la obra misma, como expresión del objetivismo escolástico y del temperamento. 
Pereda, el maestro del naturalismo español, extremó la técnica de la observación sistemática, densa, rigorismo que sólo podía encontrar su saludable contrapeso en una sensibilidad purificadora y estimulante. Es sabido que Pereda sortea los excesos del naturalismo con algunas dificultades y sus páginas aparecen hoy destinadas a los estudiosos. En cambio, Zola, padre del naturalimo científico, sigue imponiendo su valor temperamental y el acicate de su análisis tanto en lo externo como en los abismos de la condición humana. En el relato sudamericano, Carlos Reyles valoriza en la novela $\mathrm{Beba}$ una réplica del naturalismo zolesco, con las características ambientales que la definen y la salvan de la imitación servil. En Chile, Mariano Latorre, nacido bajo el hechizo de los pellines maulinos, cargó su pluma para cantar a la tierra nativa y bebió en Pereda la densidad descriptiva y el holgorio del paisaje inagotable, condiciones que convenían a su temperamento apacible. A diferencia del uruguayo, cuya obra no registra unidad estructural y estilística (recordemos el casticismo cabal de El embrujo de Sevilla), Latorre paso a paso va urdiendo y forjando una prosa de rasgos definidos que logra ganar altura y superar la frondosidad y lentitud del maestro español. Pudo influir en ello la fuerza sugestiva del paisaje chileno, que Latorre recogía en sus matices a medida que conquistaba nuevos horizontes de nuestra geografía. Vertida en su paleta abundante la arisca y cálida naturaleza de la zona central (señalemos Cuna de cóndores y Zurzulita entre otros libros), se adentra en el paisaje sureño y sus cuentos de Mapu, Tierra de mallines y La isla de los pájaros, muestran sus fondos verdeantes, húmedos $\mathrm{y}$ agoreros, sus cielos agobiados o azules, sus selvas rendidas por el hacha o el fuego. El héroe, se ha dicho con justeza, no es el hombre en las páginas de Latorre; es el medio, en cualquier punto del horizonte patrio. La intención creadora busca la vitalización por el proceso de la descripción viviente, de la metáfora yuxtapuesta y sostenida, del ritmo sonoro. A menudo, lo sabemos, recae en lo enumerativo y frío, acaso por razones psicológicas. La pupila se enerva y deja de coger la unidad cromática. Acaso en lo auditivo sea más afortunado. Pero en sus últimos 
libros se puede advertir la frescura y riqueza de su escuela, un naturalismo saludable, reparador, con atisbos de captación penetrante y de lirismo. En este punto, Latorre ya es dueño de un estilo. Sin ser un sensitivo cabal, la autovaloración, esa virtud del castigo incesante que todo humano lleva en el umbral de la conciencia, le permitió advertir sus debilidades frente a las corrientes literarias que empezaban a madurar en el tiempo. Muchos de los escritores nacidos a su sombra se asomaban al mundo de la creación literaria con distinta nervadura y personal visión. Advirtió de seguro un signo evadido en la nueva hornada de novelistas y cuentistas y midiendo el abismo naciente entre lo alcanzado por su pluma y lo ganado por los nuevos, intentó una revisión del planteamiento y del estilo, vale decir de lo externo, puesto que en lo subjetivo no cabía audacia semejante. El espíritu de la obra sostenido a lo largo de medio siglo no se altera por decisión de la mente. Sí, acaso, por vuelco del ser herido. Y así nos encontramos en Mapu, Viento de mallines y La isla do los pájaros, con períodos de viva agilidad y frases directas, cortadas desde adentro, impregnadas de luz vibrátil, certeras. El escritor no tenía más que leer y escuchar el mensaje. No hay una frase, quizás, ni una palabra salida de la pluma o de labios de un hombre pensante que no revele algo más que su primaria equivalencia. Latorre tenía la intuición musical y plástica de la prosa. Leemos en Mapu: "El sol uniforma ese paisaje, aún no conquistado por el hombre; pero si la luz empalidece, el árbol aún vivo, sonoro de hojas y de cantos de pájaros, contrasta con el palo seco, roído por la llama del roce. Mano implorante o muñón colérico, alzado en gesto de protesta". Y este trozo: "Pedacitos de selva, gordos y grávidos como los cóguiles que el estío llenó de jugosos granos obscuros. Pedacitos de sclva, tenaces y zumbadores, rozan los moscardones el cristal del aire con el torpe impulso de sus vuelos".

Con el tiempo, la paleta, más y más exigida, empezó a exprimir matices inéditos afinando los contornos de las cosas y la atmósfera que las envolvía. El escritor describía un momento en la selva y ahora se percibía la luz y la vida de la tierra en una gama menos 
fría, menos pintoresca, más sensorial e íntima. "El criollismo de Latorre -expresa Eleazar Huerta en el postfacio de La isla de los pájaros, libro póstumo- no es técnica de observación objetiva, fotografía costumbrista. Tampoco es sentimentalismo fácil, para tener al campo como algo bueno o malo, virginal o atrasado. Es creación, magia, a través de la esotería idiomática. Los datos observados, el material se ordena dócil, artísticamente, al conjuro de esa radical intuición"... "Costumbrismo basado en la intuición idiomática es la constante de Latorre y el centro de su inventiva".

Pese a esta suerte de renovación formal, el maestro reconoció más de una vez que la escuela naturalista, mal denominada "criollista" por los enemigos a causa de la preferencia de sus cultores por el motivo popular, urbano o campesino y por la generosa versión del paisaje y el ambiente nuestro, había logrado una madurez que sólo podría ser superada por la nueva generación de escritores. Recuerdo, a propósito, una entrevista que se le hiciera al maestro en un semanario santiaguino. Señalaba allí la misión que le cabía en el destino de la literatura chilena a los "neocriollistas" y nombraba a Coloane, Rojas, Jaramillo, Guzmán y al que esto escribe. La crítica nacional, cimentada en nombres tan eruditos, acuciosos y severos sin beligerancia, como Ricardo Latcham, Silva Castro, Milton Rossel, J. M. Palacios, F. Dussuel, Juan Uribe, Orlandi y otros, ha reflejado el criterio del maestro al enjuiciar en reiteradas ocasiones la obra de los escritores mencionados.

El problema del criollismo, en principio, bulle en torno a la obra y a la persona de Latorre, escritor y hombre cordial, atrayente en su postura varonil y en su charla vivaz, aliñada según el caso con metáforas que luego trascendían en el ambiente intelectual santiaguino. Definía hechos y personas, amigos y enemigos con retruécanos que sabía poner en el chascarro picante, siempre oportuno y temible. Podría decirse que en la charla estaba el criollo malicioso, con mucho de la chispa gala traída en la sangre materna, mientras que en sus libros asomaba el español depurado y enriquecido por la savia terrígena. 
Fue, quizás, esta cautivante personalidad de corrillo y sobremesa, de cátedra y conferencia la que multiplicó admiradores y contendientes en torno a una escuela literaria que sin tales excitantes hubiera caminado holgada y seguramente hacia su actual maduración. En controversia con algún crítico, la vanidad quisquillosa del censor y la ironía certera de Latorre crearon cierto clima de antagonismos acerbos. Bastó, tal vez, una apreciación, un adjetivo lanzado en cierto tono para que el humor del maestro entrase en ebullición. Podía haber quedado aquello en escaramuza, desde que la antipatía embozada en croniquillas volanderas sólo tiende a zaherir y destruir, y Latorre había sido consagrado hacía tiempo por enjuiciadores de la jerarquía de Eleodoro Astorquiza, Armando Donoso, Omer Emeth, y más tarde, por espíritus tan severos y agudos como Ricardo Latcham, Silva Castro y tantos otros. Pero las pullas y alfilerazos no pararon allí y un día empezaron a circular por corrillos y redacciones de diarios y revistas, epigramas, retruécanos, anagramas, en que aparecía el plumario criticón muy a mal traer. Al mismo tiempo, el naturalismo de Latorre era aludido por eí crítico en sus crónicas con el intencionado epíteto de "criollismo" y en este concepto, aliñado con adjetivos desdeñosos que insinuaban la supuesta ordinariez y escaso contenido artístico de la escuela, caían otros escritores en cuyos libros respiraba la vida popular.

Pocos meses antes de la muerte de Latorre (1955), a raíz de sostenídos ataques al naturalismo y realismo literarios, se promovió la llamada “querella del criollismo". La crítica ultramontana, soliviantada por la ironía de Latorre, no vaciló en lanzar la especie de que el "criollismo" era la causa de la decadencia de nuestra literatura narrativa. Se recuerda el trascendente resultado de aquella contienda, ventilada y dilucidada en un ciclo de conferencias dictadas por escritores y ensayistas de postura ideológica y sensibilidad diversas. La mal bautizada "escuela criollista" emergió de aquello renovada en espíritu y forma, pues quedó en evidencia bajo el escalpelo de unos y otros, una realidad creadora y una cosecha de valores que cimentaban y jalonaban una vigorosa literatura patria, paralela en den- 
sidad y brillo con otras de América. Fue examinada y destacada la "Generación del Centenario", en que cuentan Eduardo Barrios, Víctor Domingo Silva, Fernando Santiván, Augusto d'Halmar, Januario Espinoza y Mariano Latorre, entre otros. En seguida fue enjuiciada la promoción de 1930, que hoy bulle en afanes de obra personalísima, bajo el signo de un tiempo conmocional y evadido. El proceso de afinidad entre ambas generaciones ha sido estudiado en ocasión no lejana y definidos sus límites y proyecciones (1), así como la obra de cada uno de sus integrantes.

Existe un interrogante en el clima personal de Latorre que aún no ha sido penetrado. Cabe ahora insinuarlo, para intentar su examen en próximos trabajos, si las circunstancias lo exigen: hablo de la extraña cisura que separa la vida del hombre y la obra del escritor. Yo pude contarme entre sus amigos, compartimos alguna vez una mesa cordial, supe por él y por amigos comunes de sus afanes puramente humanos, de sus arrestos amorosos, de sus debilidades y caprichos. Fue Latorre un caso pasmoso de vitalidad derrochada en el turbión santiaguino. Su obsesión por la vida regalada tenía mucho de pintoresco y dramático. Holgaba con sus amigos y desdeñaba los compromisos a que lo llevaban admiradores vanidosos. Este clima no vive en sus libros. Existen, pues, dos mundos impermeables, ajenos, distantes. La vida de Latorre estuvo saturada de sucesos ardientes, pero sus cuentos sólo describen tipos pintorescos que se mueven en función del medio como actores subalternos dentro de un todo magníficamente ensamblado y luminoso. El sentimiento, la emoción, ¿dónde se quedaron? ¿Acaso hubo en su vida sólo la conmoción sensorial, insumisa, siempre renovada y ajena a, la emoción secreta, sin cauce, sin hondas raíces? ¿Pudo ser ésa la sola medida de su temperamento? Nunca dejará de asombrarnos esta fría transparencia de sus páginas en la que la naturaleza parece deslumbrada pero no traspasada y el hombre, los tipos, se despliegan y confunden como una pincelada más en la sinfonía cromática.

(1) "Dilucidación del criollismo", revista "Atenea", junio de 1955. 